\title{
Quick electrochemical immunoassay for hantavirus detection based on biochar platform
}

\author{
Gustavo Martins ${ }^{\mathrm{a}}$, Jeferson L. Gogola ${ }^{\mathrm{a}}$, Fabio R. Caetano ${ }^{\mathrm{a}}$, Cristiane Kalinke ${ }^{\mathrm{a}}$, Taíssa R. Jorge ${ }^{\mathrm{b}}$, \\ Claudia N.D. Santos ${ }^{\mathrm{b}}$, Márcio F. Bergamini ${ }^{\mathrm{a}}$, Luiz H. Marcolino-Junior ${ }^{\mathrm{a}, *}$ \\ ${ }^{a}$ Laboratório de Sensores Eletroquímicos (LabSensE), Departamento de Química, Universidade Federal do Paraná (UFPR), CP 19032, CEP, 81531-990 Curitiba, PR, \\ Brazil \\ b Instituto Carlos Chagas, FIOCRUZ, CEP 81310-020, Curitiba, PR, Brazil
}

\section{A R T I C L E I N F O}

\section{Keywords:}

Hantavirus

Hantavirus cardiopulmonary syndrome (HCPS)

Electrochemical immunosensor

Biochar

Quick test

\begin{abstract}
A B S T R A C T
This work describes the first method using biochar (BC) as carbonaceous platform for immunoassay application. $\mathrm{BC}$ is a highly functionalized material obtained through biomass pyrolysis under controlled conditions. Due to the highly functionalized surface, covalent binding between BC and biomolecules can be performed by EDC/NHS conjugation. The application of the modified electrode was done with Hantavirus, that are etiologic agents mainly transmitted by wild rodents. Among its pathologies Hantavirus Cardiopulmonary Syndrome (HCPS) arises at Americas, caused by Hantavirus Araucária and reaches $40 \%$ lethality. The diagnostic is based on the presence of specific hantavirus nucleoprotein (Np), under viremic condition or IgG2b antibodies (Ab), during first symptoms. The results presented a device sensitivity of $5.28 \mu \mathrm{A} \mathrm{dec}{ }^{-1}$ and a LOD of $0.14 \mathrm{ng} \mathrm{mL}^{-1}$ to the Np detection, ranging from $5.0 \mathrm{ng} \mathrm{mL}^{-1}$ to $1.0 \mu \mathrm{g} \mathrm{mL}^{-1}$, the Ab detection works as qualitative type sensor above $200 \mathrm{ng} \mathrm{mL}^{-1}$. Both sensors were evaluated its selectivity and serum samples; selectivity against Gumboro disease, VP2 protein, and antibody IgG2a against Yellow fever disease (YF), respectively. So, the devices here proposed are promising tool suitable for both rodent and human hantavirus clinical surveys.
\end{abstract}

\section{Introduction}

The main factor that impacts the electrochemical immunosensors performance is the electrode surface used as support for the immobilization of the biomolecules [1]. The biomolecules immobilization procedure is frequently linked to gold surfaces or nanoparticles due to its biocompatibility. However, protein structures do not spontaneous link it selves to the gold, it is necessary to employ SAM (Self Assembly Monolayer) structures, which acts as a bridge to attach proteins to the gold surface [2]. After this, through a crosslinking reaction, it is possible to anchor biostructures to the SAM, being EDC/NHS couple a well know reaction commonly applied to this approach [3,4].

Although, SAM use implies several drawbacks, such as the control of its formation and organization on the electrode surface. Once SAM structures are non-conductive molecules, as a result, its assemble to the electrode gradually blocks the electroactive surface. This can be avoided by using carbon-based electrodes, such as glassy carbon electrode, screen-printed carbon and carbon paste electrodes (CPE). These are attractive alternatives due to its easy of modification that allows the enhancement of sensitivity and selectivity. Herein, the direct incorporation of biomolecules can be explored through the use of materials with carboxylic groups as modifying agent $[5,6]$. Biochar $(\mathrm{BC})$ is a carbon-rich and high functionalized material, obtained from biomass pyrolysis at moderate temperatures and limited oxygen concentration [7-9]. Recent studies have shown some of its analytical applications on electroanalysis such as direct determination of metallic species $[7,10]$, organic species [11], as well as anchoring nanostructures [12] and redox mediators [13].

The main property of BC is the high amount of oxygen groups such as carboxylics, ketones, and aldehydes. These groups can be used as active sites to anchor biomolecules through the crosslinking reaction mechanism $[7,14]$. Such characteristic makes BC a very versatile platform for biosensors construction, due to the possibility of direct covalent bonding the antibodies to the BC $[15,16]$. In this context, covalent bonding an antibody enhances stability and prevents several drawbacks such as leaching the biomolecules from the device surface [17]. However, there is no report regarding the use of biochar as a platform for the development of immunosensors.

In this research, we present a label-free electrochemical immunosensor fabricated via immobilization of antibodies against

\footnotetext{
* Corresponding author.

E-mail address: luiz1berto@ufpr.br (L.H. Marcolino-Junior).
} 
Hantavirus Araucaria onto biochar modified carbon paste electrode (BCPE), in order to detect Hantavirus Araucaria nucleoprotein, targeting the presence of the antigen in rodent carriers. Furthermore is proposed a label-free immunosensor built by hantavirus nucleoprotein immobilization to detect its specific antibodies against Hantavirus Araucaria, aiming to Hantavirus Cardiopulmonary Syndrome (HCPS) diagnose HCPS during first symptoms.

Hantaviruses are emerging viruses carried by wild rodents in rural areas, its transmission to humans mainly occurs by contact with virus from infected rodents excreta [18]. The infection may cause several pathologies such as hemorrhagic fever with renal syndrome (HFRS), commonly found in the Eurasia region, and HCPS over the Americas. HCPS early diagnosis is difficult due to the unspecific symptoms like cough, fever, fatigue and muscle aches, which can be easily related to other viral diseases such as influenza [19]. Moreover, there is no specific treatment for such disease, meaning that clinical support since the first symptoms is crucial to provide intensive care.

The main factor that determines HCPS severity and course is the degree of increased permeability of infected endothelium. The immune system counters an infection through humoral and cellular response. High amounts of virus-specific IgM against Hantavirus glycoproteins, envelope proteins and Np are produced during HCPS. Furthermore, Hantavirus Np is regarded as the major viral antigen [20,21]. IgG antibodies, which represents nearly to all specific response against hantaviruses, predominantly targets viral $\mathrm{Np}$ and appears during the early convalescent phase by increasing titers $[20,22]$. However, the amount of antibody produced can be affected by various parameters and most of them are the biological characteristics of the individual, which means that there is no especific relation between antibodies concentration and the pathophysiological range.

Alongside, hantaviruses diagnosis through immunoassay response is not fast enough, as specific antibodies can only be detected from 7 to 12 days of infection, which is just after or during the first symptoms [23,24], presenting itself as a drawback for HCPS treatment, due to the disease evolution during this time. Alternatively, environmental monitoring of reservoir host can be a good approach, so the possibility of HCPS infection can be taken in consideration [25].

Currently, the standard HCPS diagnosis is performed by ELISA (Enzyme-Linked Immunosorbent Assay), usually coupled to PCR assay (Polymerase chain reaction), which presents itself as a time consuming and expensive method, and also requires trained personnel [26]. In this context, electrochemical immunosensors have shown potential application which can overcome ELISA limitations, being a simple method presenting both lower cost, in terms of equipment, inputs and biomolecules (label-free assays) and incubation time, which skip many steps when compared to ELISA assay [1].

\section{Materials and methods}

\subsection{Materials and reagents}

All chemicals were analytical or high-purity grade. Graphite powder was purchased from Fisher Chemical. $N$-(3-Dimethylaminopropyl)- $N^{\prime}-$ ethylcarbodiimidehydrochloride (EDC) and $N$-Hydroxysulfosuccinimide sodium salt (NHS) were purchased from Sigma Aldrich. Potassium hexacyanoferrate (III), Potassium nitrate, Nitric acid (70\%) and Mineral oil were purchased from Merck (Brazil). Acetate buffer, $0.10 \mathrm{~mol} \mathrm{~L}^{-1} \mathrm{pH} 4.5$, from Merck (Brazil) was used to perform EDC/NHS reaction. Hantavirus Araucaria nucleoprotein (Np), its IgG2B antibody (Ab), bovine serum album (BSA), control antigen VP2 protein from Gumboro disease and control antibody IgG2a against Yellow Fever (YF) disease were provided by Oswaldo Cruz Foundation (Fiocruz) - Curitiba, Brazil.

\subsection{Electrochemical measurements}

Electrochemical impedance spectroscopy (EIS) and voltammetry measurements were operated with a conventional three-electrode set, $\mathrm{BCPE}$ as working electrode, $\mathrm{Pt}$ plate as auxiliary electrode and $\mathrm{Ag} / \mathrm{AgCl}$ $\left(\mathrm{KCl} 3.0 \mathrm{~mol} \mathrm{~L}^{-1}\right)$ as reference electrode. Cyclic voltammetry was carried out in presence of the electrochemical probe $\mathrm{K}_{3}\left[\mathrm{Fe}(\mathrm{CN})_{6}\right]$, with $\mathrm{KNO}_{3} 0.1 \mathrm{~mol} \mathrm{~L}^{-1}$ as electrolyte, potential range from $-0.20-0.65 \mathrm{~V}$, and scan rate of $50 \mathrm{mV} \mathrm{s}^{-1}$. Voltammetry and EIS experiments were performed on a potentiostat galvanostat Metrohm AUTOLAB PGSTAT128 N. Electrochemical impedance spectroscopy (EIS) was operated in $1.0 \mathrm{mmol} \mathrm{L}^{-1} \mathrm{~K}_{3}\left[\mathrm{Fe}(\mathrm{CN})_{6}\right]$ at a frequency range of $0.1 \mathrm{~Hz}$ to $100 \mathrm{kHz}$ with $10 \mathrm{mV}$ AC amplitude and potential condition equivalent to the $\mathrm{K}_{3}\left[\mathrm{Fe}(\mathrm{CN})_{6}\right]$ cathodic peak.

\subsection{Preparation and characterization of biochar $(B C)$}

BC was obtained following the methodologies described by Rezende et al. [27] and Kalinke et al. [28]. Firstly, castor bean was grounded in a ball mill and separated by $40-80$ mesh sieve, the powder obtained (castor bean) was submitted to pyrolysis under low oxygen condition, in EDG FT-40 oven, during $60 \mathrm{~min}$ at $400{ }^{\circ} \mathrm{C}$, with a heating rate of $5{ }^{\circ} \mathrm{C}$ $\min ^{-1}$. Aiming to increase oxygen-containing functional groups moieties, and reasonably adsorptive capability, BC sample was submitted to chemical activation by acidic oxidation with nitric acid $3.0 \mathrm{~mol} \mathrm{~L}^{-1}$ under reflux condition, at $60^{\circ} \mathrm{C}$ over $3 \mathrm{~h}$ [7], obtaining treated biochar.

Surface area and pore size data were obtained through Quantachrome porosimeter New 1200 model and their distribution by B.E.T. method (Brunauer, Emmett and Teller). FTIR spectra for structural characterization were carried out using a BOMEN spectrophotometer, spectral range from $4000 \mathrm{~cm}^{-1}$ to $500 \mathrm{~cm}^{-1}$. BC and treated $\mathrm{BC}$ total acid groups were investigated by itration method based on Boehm procedure [29]. The procedure for both samples, BC and treated $\mathrm{BC}$, involves a retro-titration using sodium hydroxide for the quantification of total surface acids. Initially, $100 \mathrm{mg}$ sample was added into $10 \mathrm{~mL}$ of $0.1 \mathrm{~mol} \mathrm{~L}^{-1} \mathrm{NaOH}$ and kept under stirring for $6 \mathrm{~h}$. Subsequently, the sample was filtered and washed, then $10 \mathrm{~mL}$ of $0.1 \mathrm{~mol} \mathrm{~L}^{-1} \mathrm{HCl}$ was added and stirred for $1 \mathrm{~h}$. Subsequently, the potentiometric titration was performed, using Metrohm tritino automatic titrator, with $0.1 \mathrm{~mol} \mathrm{~L}^{-1} \mathrm{NaOH}$ solution.

\subsection{Preparation of carbon paste electrode modified with $B C$}

The carbon paste electrode modified with treated BC (BCPE) was prepared through homogenization of $25 \%(\mathrm{w} / \mathrm{w})$ mineral oil, $55 \%(\mathrm{w} /$ w) graphite powder and $20 \%(\mathrm{w} / \mathrm{w})$ treated $\mathrm{BC}$ in a mortar with pistil. The treated BC paste was packed into the hole of the electrode body (PVC support pipe. $\Phi=3.0 \mathrm{~mm}$ ), which was filled with a metallic copper wire as electric contact. Then, BCPE surface was smoothed on a clean paper until it had a flat appearance. In order to compare electrochemical performance, non-modified CPE was also prepared (proportion of $25 \%(\mathrm{w} / \mathrm{w})$ mineral oil and $75 \%(\mathrm{w} / \mathrm{w})$ graphite powder).

\subsection{Construction of the hantavirus immunosensors}

For preparation of the Hantavirus immunosensors, firstly BCPE was submitted to EDC and NHS reaction, yielding o-acylisourea intermediate which activate BCs carboxylic groups to amidation reaction with biomolecules. This step was performed by prepare an EDC and 
NHS solution, both $5.0 \mathrm{mmol} \mathrm{L}^{-1}$, in acetate buffer solution $0.1 \mathrm{~mol} \mathrm{~L}^{-1}, \mathrm{pH}$ 4.5. Then, the BCPE was immersed in this solution, during 15 min under stirring condition. Subsequently, the antibody was added to the BCPE surface through dropcasting of $5.0 \mu \mathrm{L}$, from the main Ab solution $\left(0.40 \mathrm{mg} \mathrm{mL}^{-1}\right)$, followed by incubation with BSA solution $\left(1.00 \mathrm{mg} \mathrm{mL}^{-1}\right)$. This immunosensor device was called BCPE - Ab, aiming detect the nucleoprotein. A second device was built immobilizing the nucleoprotein using the same procedure described above (BCPE - Np) aiming to detect specific antibodies.
3. Results and discussion

\subsection{Structural characterization of biochar $(B C)$}

To evaluate the effectiveness of acid functionalization on BC surface, oxygen groups were quantified by a procedure inspired on Boehm titration [7]. The acidic content of $\mathrm{BC}$ was found to be $4.02 \mathrm{mmol} \mathrm{g}^{-1}$ before and $7.26 \mathrm{mmol} \mathrm{g}^{-1}$ after chemical oxidative treatment, which indicates that treatment plays an important role increasing significantly

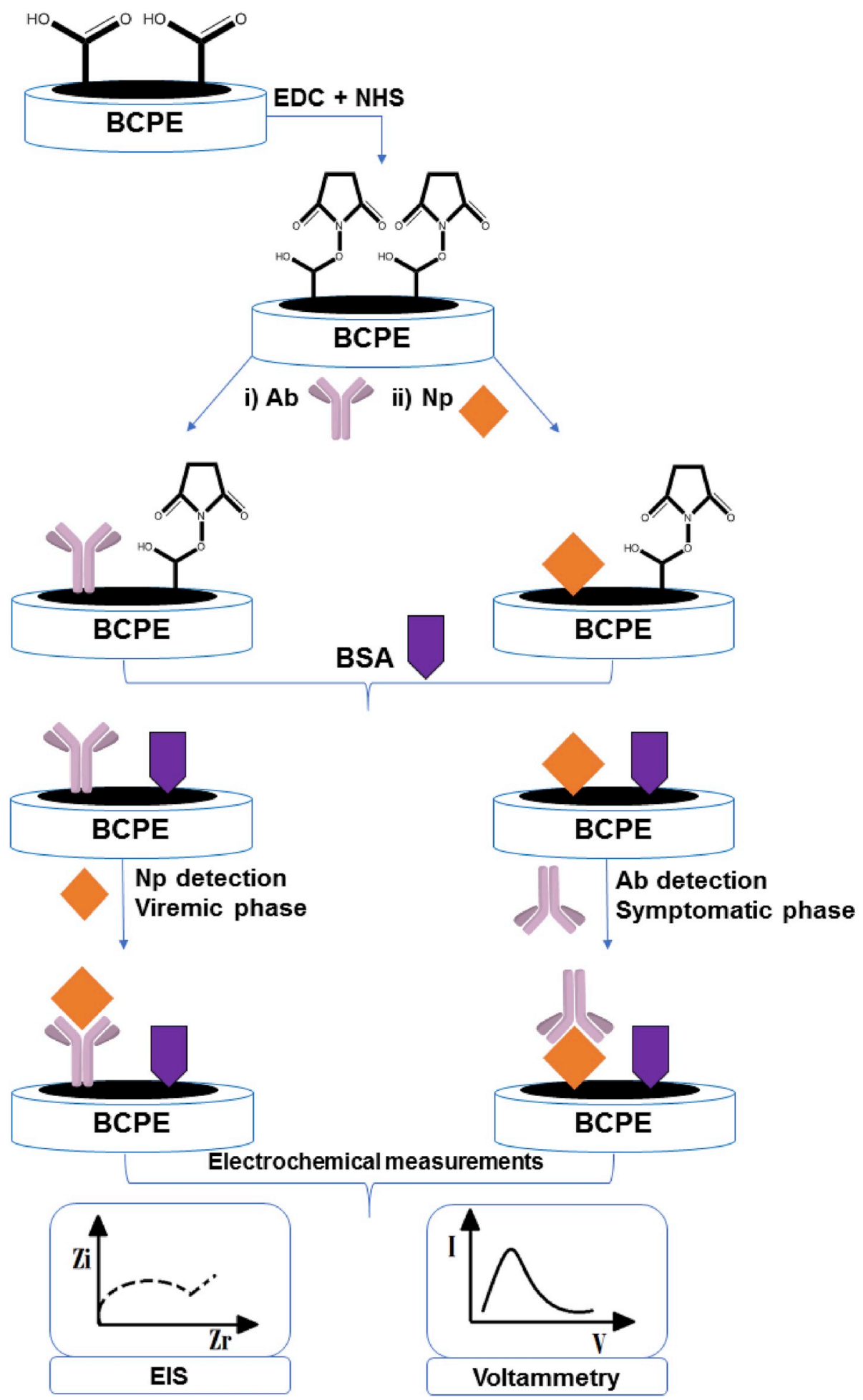

Scheme 1. Schematic illustration of both immunosensors configuration. 
the total acids groups at BCs surface. Since BC is being employed as an electrode modifier, the treatment increases oxygen groups available for biomolecules binding on the biochar.

BCs' surface properties such as surface area and pore volume were obtained from B.E.T analysis (Table S1). The chemical treatment changes $\mathrm{BC}$ textural properties leading to higher pore size, that is related to the oxidation promoted by the treatment with $\mathrm{HNO}_{3}$, this process mostly forms oxygen groups at the pore walls, causing its collapse [30]. In addition, FTIR spectroscopy was employed to investigate the variation of functional groups at the surface of three different materials (biochar (before/after) chemical treatment and after EDC/NHS activation), shown in the supplementary material (Fig. S1).

FTIR spectra obtained for untreated and treated samples presents a broad band around $3300 \mathrm{~cm}^{-1}$, attributed to $\mathrm{O}-\mathrm{H}$ bond stretch, another dominant feature at 1750,1450 and $1090 \mathrm{~cm}^{-1}$ were attributed to an asymmetric stretch of $\mathrm{C}=\mathrm{O}, \mathrm{O}-\mathrm{H}$ and $\mathrm{C}-\mathrm{O}$ bonds respectively from phenols and carboxylic acids [31]. After acid functionalization, at $3300 \mathrm{~cm}^{-1}$ the band showed an enlargement, which represents $\mathrm{O}-\mathrm{H}$ stretch from carboxylic acids [31]. The $1750-1500 \mathrm{~cm}^{-1}$ wavenumber region shows similar behavior with higher intensity. Herein, after the treatment BC showed a band around $1300-1180 \mathrm{~cm}^{-1}$, which represents $\mathrm{C}-\mathrm{O}$ bond stretch, that may be related to the acid treatment [31].

After the EDC/NHS reaction, $3300 \mathrm{~cm}^{-1}$ band split into two other bands around 3422 and $3142 \mathrm{~cm}^{-1}$ which are related to N-H stretch from primary and secondary amines and amides from EDC and NHS intermediate bounding onto BC carboxylic [32]. Furthermore, $1750-1500 \mathrm{~cm}^{-1}$ region, which corresponds to carboxylic, ketones and lactones, shows a significant change. The bands at these wavenumber region after EDC and NHS activation shows overlapping, especially at 1620 and $1530 \mathrm{~cm}^{-1}$ region attributed to the deformation frequency of primary amines, from the EDC and NHS [33].

\subsection{Immunosensor construction and characterization}

Two strategies were adopted and evaluated, as can be seen at Scheme 1: I) Antibodies (Ab) anchoring on BCPE surface for nucleoprotein $(\mathrm{Np})$ detection (BCPE - Np), and II) Np anchoring on BCPE surface for $A b$ detection (BCPE - Np). All steps involved on the immunosensor construction were characterized by cyclic voltammetry (CV) and electrochemical impedance spectroscopy (EIS) measurements based on $\left[\mathrm{Fe}(\mathrm{CN})_{6}\right]^{4-/ 3-}$ redox probe profile.

Fig. 1A shows the cyclic voltammograms of the immunosensor assembly process. Firstly, the interaction of carboxylic groups on the BC surface with EDC/NHS was evaluated. The intensity of current peak for $\left[\mathrm{Fe}(\mathrm{CN})_{6}\right]^{4-/ 3-}$ redox probe showed a significative increase after the crosslink reaction with EDC/NHS when compared to the BCPE signal (black to blue lines). Similar results were previously reported by Pauliukaite et al. [34], which indicates surface activation by EDC/NHS intensifies $\left[\mathrm{Fe}(\mathrm{CN})_{6}\right]^{4-/ 3-}$ redox processes compared to other activation methods. The same behavior was observed in Fig. 1B (EIS measurements) reporting more effective electron transfer of redox probe for the BCPE after EDC/NHS reaction, with a calculated resistance of charge transfer $\left(\mathrm{R}_{\mathrm{ct}}\right)$ of $15.8 \mathrm{k} \Omega-4.7 \mathrm{k} \Omega$. Those results support the indicative that carboxylic groups on BC surface were activated by EDC/NHS, as previously suggested by FTIR measurements.
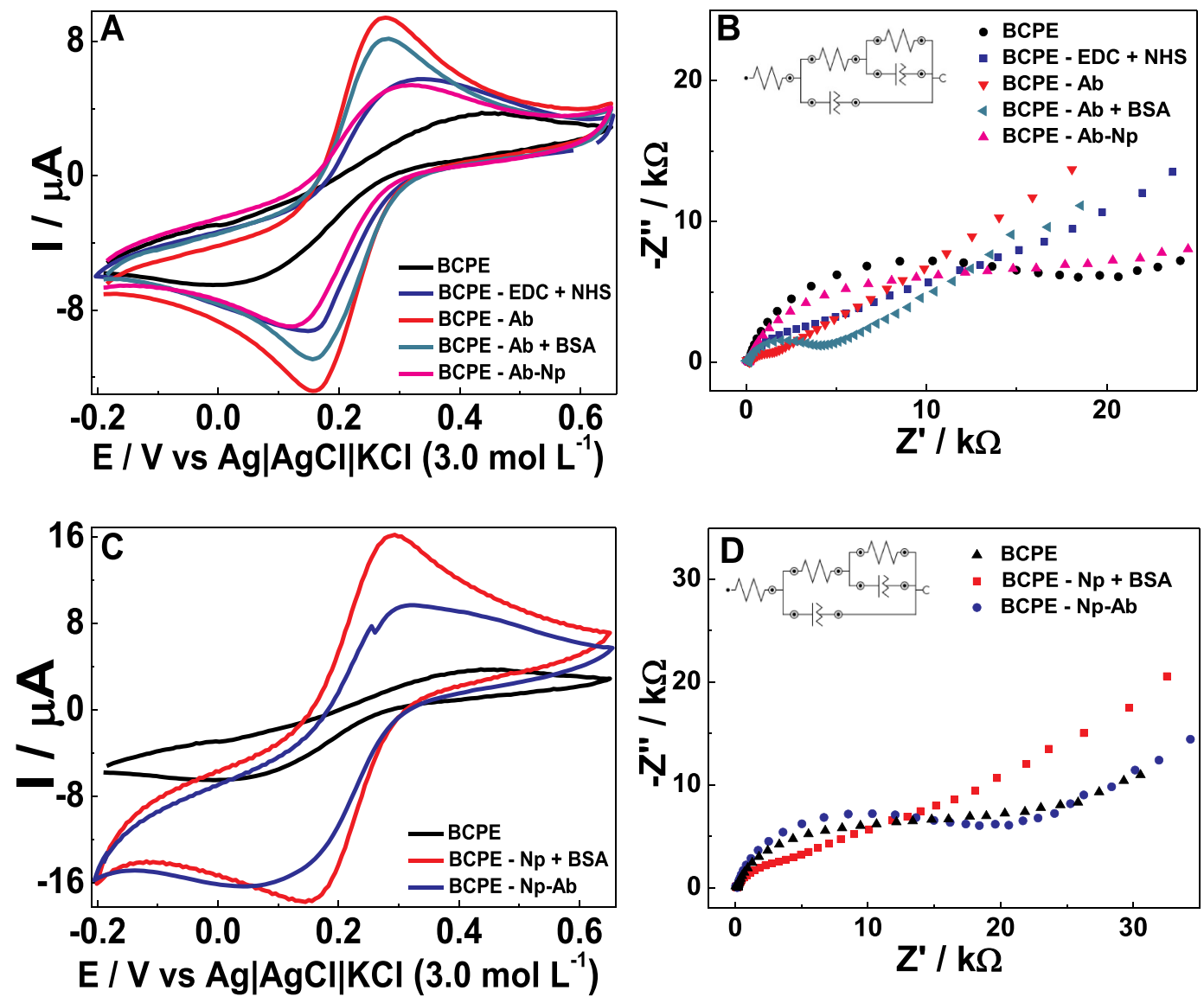

Fig. 1. (A) Cyclic voltammograms obtained with BCPE to each modifying process, until $\mathrm{Ab}$ anchoring and NP detection, with $\mathrm{K}_{3}\left[\mathrm{Fe}(\mathrm{CN})_{6}\right] 0.1 \mathrm{mmol} \mathrm{L}^{-1}, 50 \mathrm{mV} \mathrm{s}^{-1}$. (B) EIS obtained for BCPE to each modifying process, until Ab anchoring and NP detection, with $\mathrm{K}_{3}\left[\mathrm{Fe}(\mathrm{CN})_{6}\right] 0.1 \mathrm{mmol} \mathrm{L}^{-1}$, open circuit condition. (C) Cyclic voltammograms obtained for BCPE to each modifying process, until NP anchoring and Ab detection, with $\mathrm{K}_{3}\left[\mathrm{Fe}(\mathrm{CN})_{6}\right] 0.1 \mathrm{mmol} \mathrm{L}^{-1}, 50 \mathrm{mV} \mathrm{s}^{-1}(\mathrm{D}) \mathrm{EIS}$ obtained with BCPE to each modifying process, until NP anchoring and Ab detection, with $\mathrm{K}_{3}\left[\mathrm{Fe}(\mathrm{CN})_{6}\right] 0.1 \mathrm{mmol} \mathrm{L}^{-1}$, open circuit condiction. 
After the surface activation process, the $\mathrm{Ab}$ anchoring by amidation reaction was evaluated. In this case, $\mathrm{Ab}$ was added to the BCPE activated by EDC/NHS surface by dropcasting, followed by CV and EIS measurements. As shown in Fig. 1A (red line), after Ab anchoring, the current peak showed an enhancement, increasing redox probe signals. In addition, EIS data express a similar effect, in Fig. 1B, lower resistance to charge transfer $(1.5 \mathrm{k} \Omega)$ when compared to BCPE. Such results indicate that Ab was successfully anchored at the BCPE surface, likely due to that Hantavirus antibodies occupy carboxylic groups, the negatively charged groups in $\mathrm{BC}$, and reasonably decreases the electrostatic repulsion between $\left[\mathrm{Fe}(\mathrm{CN})_{6}\right]^{4-/ 3-}$ and the electrode surface $[35,36]$.

The next step was BSA anchoring, aiming to bond non-specific sites and substitute residual EDC/NHS after Ab immobilization. Fig. 1A (green line) shows a small decrease in the current peak, that indicates BSA immobilization, since it partially blocks the electrode surface [37]. It is confirmed in Fig. $1 \mathrm{~B}$, by a calculated $\mathrm{R}_{\mathrm{ct}}$ of $3.8 \mathrm{k} \Omega$ after BSA immobilization, which suggests that few non-specific sites are left after the blockage, leading to a small difference in the current peak and the resistance.

After BSA immobilization step, the Np detection occurs based on a selective $\mathrm{Ab}-\mathrm{Np}$ immunocomplex formation. The couple formation (Ab$\mathrm{Np}$ ) promotes a partial blockage of the surface. Since a layer of biomolecules is added to the electrode, it affects the interaction between electrode surface and the redox probe, reasonably it leads to a lower effective conversion of the redox probe and consequently a slight decrease of the current peak (Fig. 1A, rose line). In agreement with $\mathrm{CV}$ studies, EIS measurements (Fig. 1B) shows an increase in chargetransfer resistance to $9.7 \mathrm{k} \Omega$, caused by this surface blockage after the immunocomplex formation. These data also indicated that the antibody was successfully bounded onto the electrode surface.

However, Np detection is useful to confirm the presence of virus in rodent carriers blood and urine but, this approach can not be used as a diagnosis method in humans. Taking into consideration that viruses are intracellular parasites, its nucleoproteins concentrate exists mostly inside cells, thus present a limited amount on bloodstream [25]. For this purpose, a second strategy was carried out aiming to detect specific antibodies (Ab). The specific antibodies against the hantavirus can be detected in the bloodstream during the first symptoms, consequently, it helps an early diagnosis, which leads to a targeted clinical intervention [38].

Antibodies (Ab) detection approach was evaluated by immobilizing the nucleoprotein on BCPE to detect hantavirus antibodies. After Np immobilization onto BCPE activated by EDC/NHS, cyclic voltammograms (Fig. 1C) showed a higher current peak to the probe redox processes when compared to the blank electrode, which indicates a successful Np immobilization. The current peak after immunocomplex formation presents lower magnitude due to the blockage of BCPE surface. Similar resistivity effects were observed to $R_{c t}$ (Fig. 1D) presenting lower charge-transfer resistance after $\mathrm{Np}$ immobilization $(16.4 \mathrm{k} \Omega$ for $\mathrm{BCPE}, 3.3 \mathrm{k} \Omega$ for BCPE-Np) and $\mathrm{R}_{\mathrm{ct}}$ increase to $12.3 \mathrm{k} \Omega$ for BCPE - Np -Ab.

In order to confirm the effectiveness and stability of protein anchoring on BCPE surface, the $\mathrm{CV}$ behavior of $\left[\mathrm{Fe}(\mathrm{CN})_{6}\right]^{3-/ 4-}$ were recorded for both CPE unmodified electrode (graphite and mineral oil) and BCPE before and after Np immobilization. Results are shown in Fig. 2.

The voltammetric behavior of $\left[\mathrm{Fe}(\mathrm{CN})_{6}\right]^{3-/ 4-}$ was very similar after the first cycle for both electrode configuration (Fig. 2A and C) indicating that redox process probably occurs by the same pathway on both electrodes. However, after consecutive cycles, an expressive reduction on the current peak intensity was observed for the CPE, probably caused by gradual leaching of the nucleoprotein from the electrode surface, since graphite presents few oxygenated functional groups able to react with the crosslinker agent [39]. In this case, most of the protein
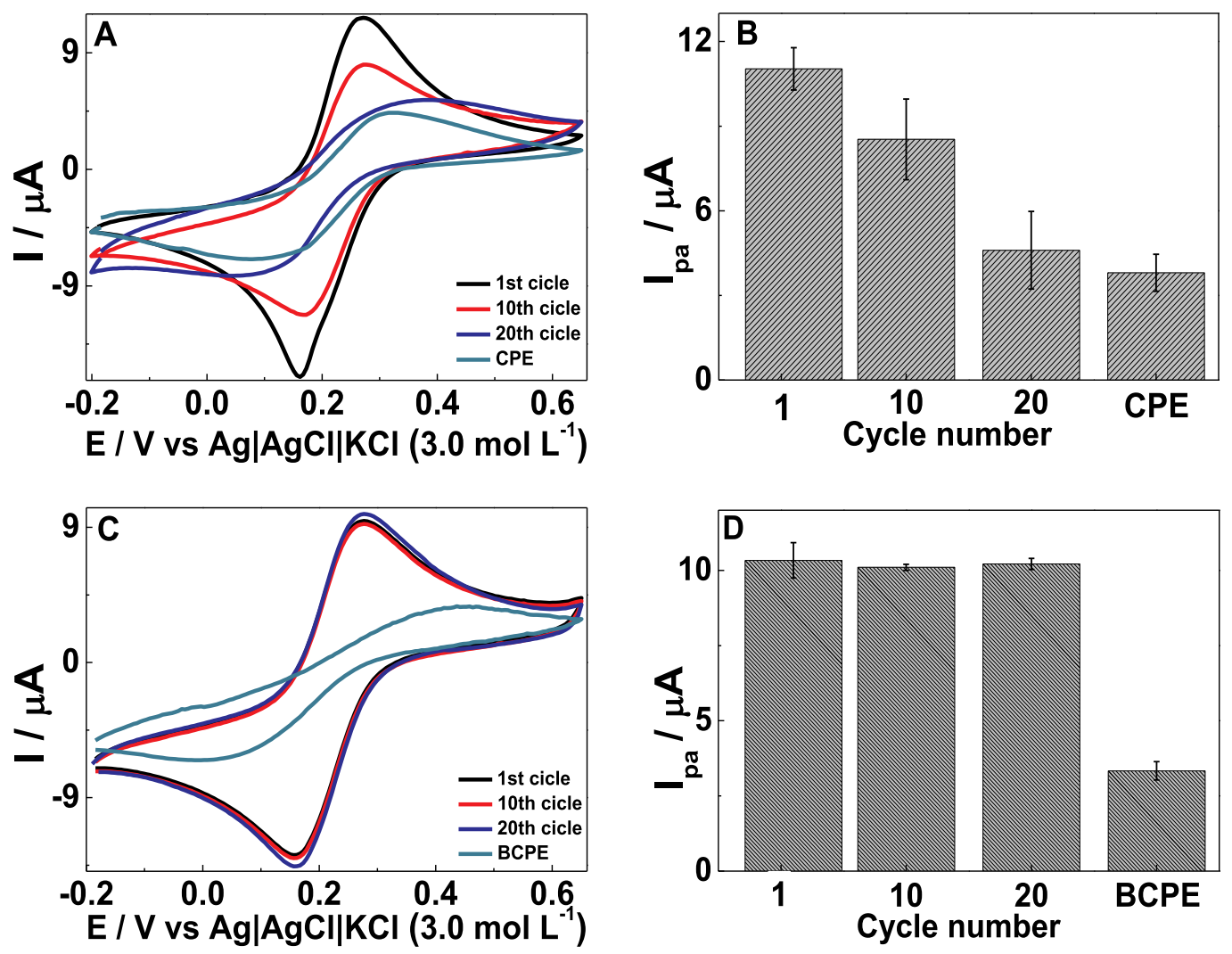

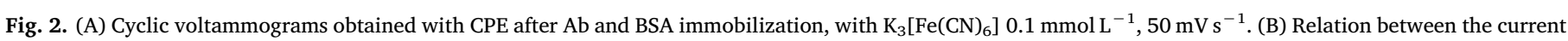

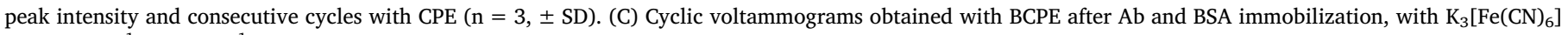
$0.1 \mathrm{mmol} \mathrm{L}^{-1}, 50 \mathrm{mV} \mathrm{s}^{-1}$. (D) Relation between the probe current peak intensity and consecutive cycles with BCPE (n $=3, \pm \mathrm{SD}$ ). 
is weakly adsorbed onto the electrode surface, which can be easily removed from the electrode surface. For BCPE, after consecutive CV measurements, no significative decreasing of current peaks was observed, confirming the effectiveness of protein anchoring on the BCPE surface. Such results indicate the biochar's good ability to anchor biological materials as proteins.

\subsection{Experimental conditions optimization}

Since Biochar is a new platform for protein immobilization, a systematic study of relevant parameters of immunosensors construction and electrochemical detection were performed to achieve the best experimental conditions. The optimized experimental conditions are shown in Table S2 (see supporting information section).

The effectiveness of biomolecule immobilization and the electrochemical behavior of the redox mediator are solution and $\mathrm{pH}$ dependent. The solution $\mathrm{pH}$ and time of EDC/NHS reaction followed by $\mathrm{Ab}$ conjugation were evaluated by $\mathrm{CV}$ technique using $\left[\mathrm{Fe}(\mathrm{CN})_{6}\right]^{3-/ 4-}$ as redox probe and $\mathrm{KNO}_{3} 0.1 \mathrm{~mol} \mathrm{~L}^{-1}(\mathrm{pH}$ solution varying from 2.0 to 7.4) was used as supporting electrolyte, since is a non-amine and noncarboxylate solution. EDC/NHS reaction $\mathrm{pH}$ was investigated based on probe current intensity. The probe current responses increased rapidly with the $\mathrm{pH}$ value from 2.0 to 4.5 , and then decreased at higher $\mathrm{pH}$ condition. Such behavior can be interpreted as a balance between the optimum $\mathrm{pH}$ for carboxylic conjugation of BCPE with EDC producing oacylisourea intermediate, since the pKa of carboxylic groups of BCs are normally in the range of 4.0 to $8.0[30,40]$. However, the intermediate o-acylisourea is not reactive enough towards primary amines [41], but can be easily replaced by NHS, through a nucleophilic attack, which stably bonds to carboxylics and efficiently reacts to primary amines. NHS replace by primary amines, proteins (e.g Ab/Np), has its optimum $\mathrm{pH}$ range from 4.5 to 7.0 [42]. On the other hand, biomolecules are usually handled at stock $\mathrm{pH}$ around physiological ( $\sim 7.4)$, which was chosen for biomolecule immobilization to provide standard conditions influencing the conformation of the proteins.

Considering that calibration curve shows the decrease of redox probe signal as a function of immunocomplex formation, $\left[\mathrm{Fe}(\mathrm{CN})_{6}\right]^{3-/ 4-}$ concentration was evaluated to achieve the widest linear range of electrochemical response. In this case, it was fixated Np concentration on $5.0 \mathrm{ng} \mathrm{mL}^{-1}$ and increased probe concentration from 0.5 to $2.5 \mathrm{mmol} \mathrm{L}^{-1}$. The optimized condition was found at $2.0 \mathrm{mmol} \mathrm{L}^{-1} \mathrm{pH}$ influence on probe detection was also verified by $\mathrm{CV}$, and BCPE - Ab showed the best results at $\mathrm{pH}$ 3.0.

Biomolecule's immobilized mass study was carried out on both configurations to verify the effect of varying its amount, onto BCPE (BCPE - Ab/BCPE - Np), to the probe current signal into CV. CV results showed a linear positive dependency from $I_{a p}$ to the biomolecules amount, until it reaches a maximum of current intensity, which points to the optimal protein mass value. Above this mass value implies on a current peak decrease, that indicates blockage of the electroactive surface. Therefore, the optimal amount value for $\mathrm{Np}$ and $\mathrm{Ab}$ immobilization were of 2.00 and $5.95 \mu \mathrm{g}$, respectively. The effect of BSA concentration on the blockage of nonspecific sites was also evaluated and the concentrations studied showed no significant effect on the electrochemical responses. Therefore, the lower evaluated concentration $\left(1.00 \mathrm{mg} \mathrm{mL}^{-1}\right)$ was chosen for further studies.

\subsection{Electrochemical response of the immunosensors}

To evaluate the analytical performance of the developed immunosensor, different concentrations of $\mathrm{Ab}$ standard solutions were incubated and measured under the optimal experimental condition. Fig. 3A displayed $\mathrm{CV}$ responses recorded using the immunosensor (BCPE - Ab) to Np for increasing concentrations. The electrochemical response of $\left[\mathrm{Fe}(\mathrm{CN})_{6}\right]^{3-/ 4-}$ decreased as the $\mathrm{Np}$ concentrations increased, for antigen-antibody complex acting as an inert kinetic barrier for the electron-transfer. As shown in Fig. 3B, the CV peak current was proportional to the logarithm of $\mathrm{Np}$ concentration in the range of $5.0 \mathrm{ng} \mathrm{mL}^{-1}$ to $1.0 \mu \mathrm{g} \mathrm{mL}^{-1}$. Through the data recorded by $\mathrm{CV}$ was possible to build a calibration curve (Fig. 3B) that relates the difference of the peak height from the redox probe to the logarithmic concentration, leading to a calculated sensitivity of $5.28 \mu \mathrm{A} \mathrm{dec}{ }^{-1}$ and a LOD calculated ( $3 \mathrm{SD}_{\text {blank }} /$ slope) equals to $0.14 \mathrm{ng} \mathrm{mL}^{-1}$.

The BCPE - Np performance, Fig. 3C, was also evaluated to detect $\mathrm{Ab}$. CV registered showed a significant decrease in the voltammetric signal for concentrations above $200 \mathrm{ng} \mathrm{mL}^{-1}$. When higher $\mathrm{Ab}$ concentrations were used, no changes on voltammetric signal were observed. However, its application still can be evaluated as a qualitative sensor. As shown in Fig. 3D, it can be established a cutoff value, $45 \%$ of the current signal, which can be applied as an indicative to the presence of antibodies against hantavirus. Both devices qualitative application depends on the selectivity because a selective sensor would respond only to the immunocomplex formation, independent of the concentration.

\subsection{Selectivity, reproducibility and stability}

To evaluate the selectivity of the developed immunosensor, voltammetric measurements were carried out using a control antigen and antibody (Fig. 4). Control biomolecules have the same basic structure of the studied biomolecules, except by the antibody epitope and the actives antigenic sites, often responsible for the immunocomplex formation.

As shown in Fig. 4A, BCPE - Ab correspond to redox probe signal before the immunocomplex formation. After the incubation of BCPE $\mathrm{Ab}$ in presence of quantitative excess of VP2 $\left(0.32 \mathrm{mg} \mathrm{mL}^{-1}\right)$, which did not show significant difference to the current peak intensity, indicating that protein did not interact with Ab. To verify the immunosensor response after a possible interference of VP2, the Np $\left(10.0 \mathrm{ng} \mathrm{mL}^{-1}\right)$ was added to the system and an expressive variation of the redox probe current was observed. These results indicate a good selectivity of the developed immunosensor demonstrating that the proposed device can be used to differentiate the hantavirus nucleoprotein from another similar nucleoprotein, and therefore eligible to be tested with samples.

To BCPE - Np, Fig. 4B, similar behavior was observed when targeting specific antibodies against hantavirus. It was verified that the control antibody (YF $-0.16 \mathrm{mg} \mathrm{mL}^{-1}$, stock solution) did not interact with $\mathrm{Np}$, since there was no significant difference between the signal data obtained to BCPE-Np and the control antibody. On the other hand, specific $\mathrm{Ab}\left(200 \mathrm{ng} \mathrm{mL}^{-1}\right)$ and the mixture, $\mathrm{Ab}\left(200 \mathrm{ng} \mathrm{mL}^{-1}\right)$ and control antibody $\left(0.16 \mathrm{mg} \mathrm{mL}^{-1}\right)$, showed a decrease to the BCPE-Np signal, which suggests that only specific $\mathrm{Ab}$ against hantavirus nucleoprotein interacts efficiently with the Np sites. In this context, the proposed devices showed good selectivity to the control proteins and therefore both configurations were tested in human blood serum samples.

The commercial human serum sample contain proteins and other species, whose may provide unspecific interaction with the devices; this interaction can result in signal interference, due to nonspecific binding. Therefore, in order to simulate a clinical assay, human serum samples were spiked, and the CV measurements were performed in a 1:100 dilution condition. Fig. $4 \mathrm{C}$ shows the results obtained with BCPE- $\mathrm{Ab}$ in presence of a fortified sample of $\mathrm{Np}\left(100 \mathrm{ng} \mathrm{mL}^{-1}\right)$ and Fig. 4D shows results obtained to the BCPE-Np in presence of a fortified sample of $\mathrm{Ab}$ $\left(200 \mathrm{ng} \mathrm{mL}^{-1}\right)$. At both devices, the difference in the signal obtained from serum to the spiked sample was a consequence of the specific interaction between $\mathrm{Np}-\mathrm{Ab}$ (immunocomplex), which leads to a thicker layer at the devices surface and decrease of the current intensity. So, these results demonstrate the effective applicability of the proposed immunosensor based on biochar. 

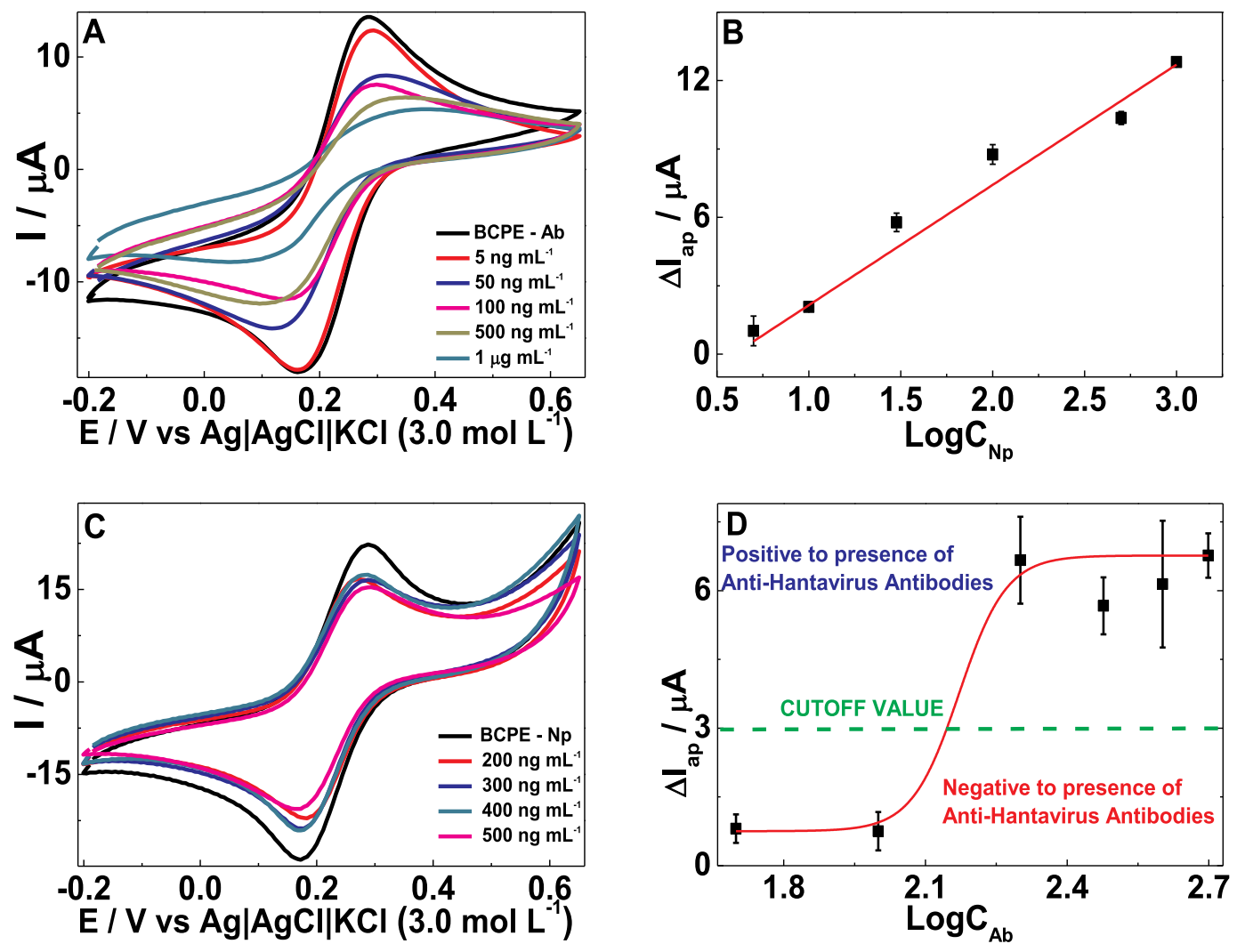

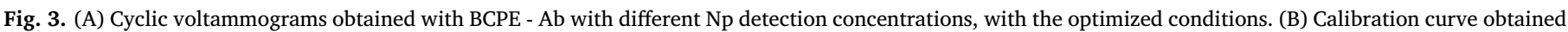

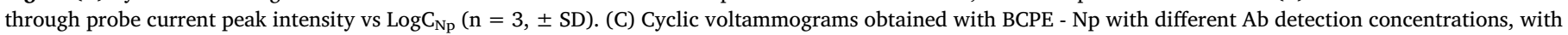
the optimized condictions. (D) Calibration curve obtained through probe current peak intensity $v \log C_{A b}(n=3$, $\pm S D)$.
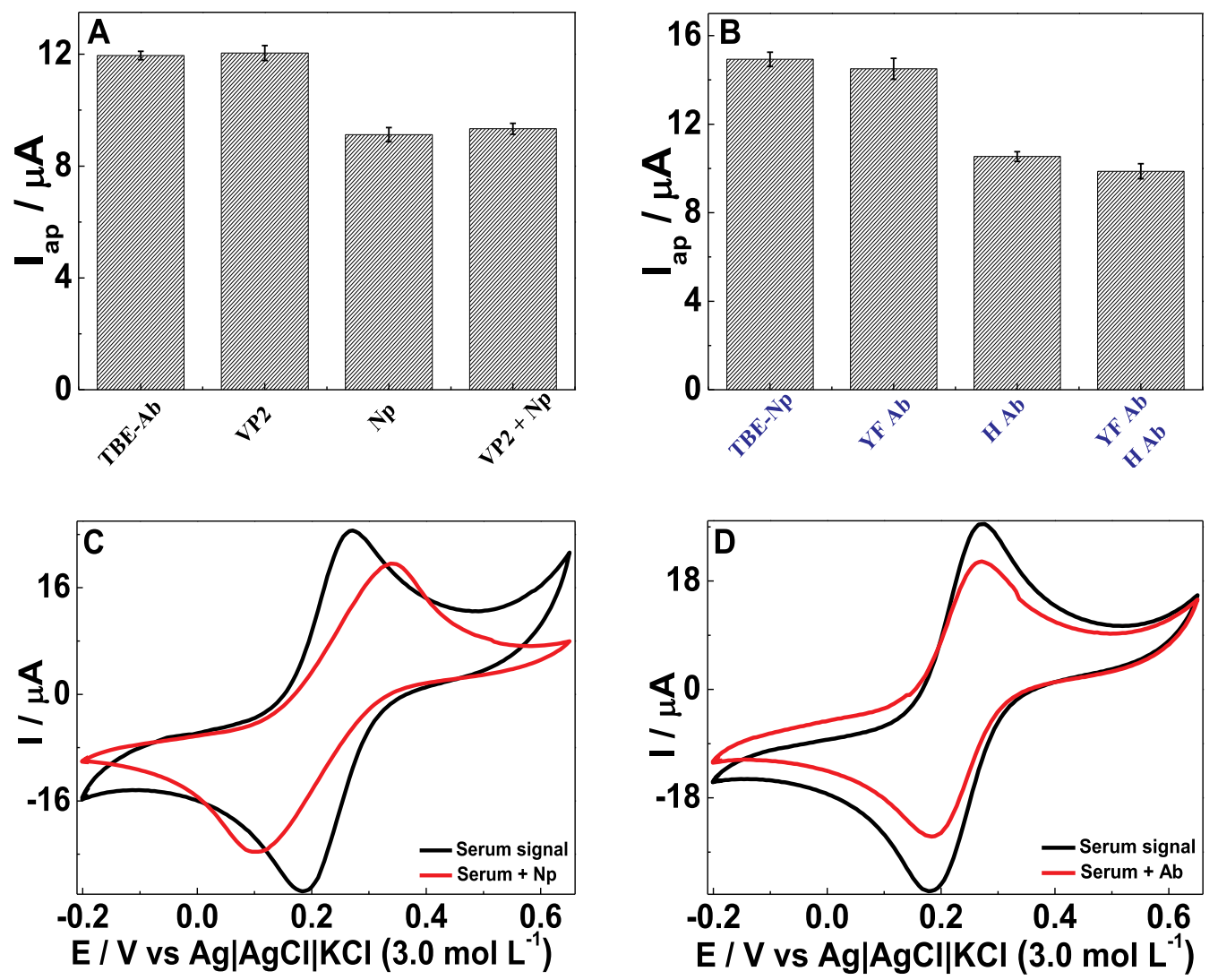

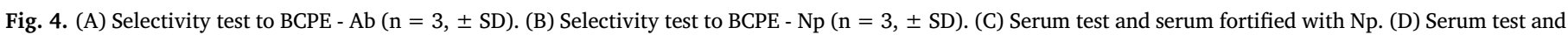
serum fortified with $\mathrm{Ab}$. 


\section{Conclusion}

Biochar (BC) is a carbonaceous material with a rising number of applications, and here the potentiality of a biochar-based immunosensor was firstly described. This highly functionalized material showed to be both suitable to immobilize biomolecules and maintenance of biological activity. The ease of anchoring biomolecules allied to the possibility of a label-free configuration provided by electrochemical techniques was successfully explored with the use of hantavirus nucleoprotein/specific antibody pair to build an electrochemical immunosensor. Two devices were tested, one with the virus nucleoprotein immobilized and other with the antibody, both aimed to detect its complement by the formation of the immunocomplex and provide wide potential applications for the detection of hantavirus nucleoprotein or IgG antibodies in clinical diagnosis and also can be applied to verify wild rodents infections.

Furthermore, both sensors showed an easy of build and the possibility to realize in site tests. Its operation requires a reduced sample volume, which represents lower costs in overall terms, and rapid analysis time. Reasonably the proposed showed itself suitable for the development of POCT devices and its application to immediate diagnose an individual's condition, that facilitate treatment decisions [43].

\section{Acknowledgments}

The authors acknowledge the financial support by CNPq (454594/ 2014-3). This study was financed in part by the Coordenação de Aperfeiçoamento de Pessoal de Nível Superior - Brasil (CAPES) Finance Code 001, NENNAM (PRONEX, Fund. Araucária/CNPq) and the Molecular Virology Laboratory at Carlos Chagas Institute FIOCRUZ/PR.

\section{Appendix A. Supplementary data}

Supplementary data to this article can be found online at https:// doi.org/10.1016/j.talanta.2019.05.101.

\section{References}

[1] F. Ricci, G. Adornetto, G. Palleschi, A review of experimental aspects of electrochemical immunosensors, Electrochim. Acta 84 (2012) 74-83, https://doi.org/10 1016/j.electacta.2012.06.033.

[2] H. Wang, H. Ohnuki, H. Endo, M. Izumi, Effects of self-assembled monolayers on amperometric glucose biosensors based on an organic-inorganic hybrid system, Sensor. Actuator. B Chem. 168 (2012) 249-255 https://doi.org/10.1016/j.snb. 2012.04.018.

[3] K.A. Totaro, X. Liao, K. Bhattacharya, J.I. Finneman, J.B. Sperry, M.A. Massa, J. Thorn, S.V. Ho, B.L. Pentelute, Systematic investigation of EDC/sNHS-mediated bioconjugation reactions for carboxylated peptide substrates, Bioconjug. Chem. 27 (2016) 994-1004, https://doi.org/10.1021/acs.bioconjchem.6b00043.

[4] P. Skládal, Advances in electrochemical immunosensors, Electroanalysis 9 (1997) 737-745, https://doi.org/10.1002/elan.1140091002.

[5] L. Bareket, A. Rephaeli, G. Berkovitch, A. Nudelman, J. Rishpon, Carbon nanotubes based electrochemical biosensor for detection of formaldehyde released from a cancer cell line treated with formaldehyde-releasing anticancer prodrugs, Bioelectrochemistry 77 (2010) 94-99, https://doi.org/10.1016/j.bioelechem.2009. 06.016.

[6] S.K. Tuteja, T. Duffield, S. Neethirajan, Graphene-based multiplexed disposable electrochemical biosensor for rapid on-farm monitoring of NEFA and $\beta$ HBA dairy biomarkers, J. Mater. Chem. B. 5 (2017) 6930-6940, https://doi.org/10.1039/ C7TB01382E.

[7] C. Kalinke, P.R. Oliveira, G.A. Oliveira, A.S. Mangrich, L.H. Marcolino-Junior, M.F. Bergamini, Activated biochar: preparation, characterization and electroanalytical application in an alternative strategy of nickel determination, Anal. Chim. Acta 983 (2017) 103-111, https://doi.org/10.1016/j.aca.2017.06.025.

[8] M. Tripathi, J.N. Sahu, P. Ganesan, Effect of process parameters on production of biochar from biomass waste through pyrolysis: a review, Renew. Sustain. Energy Rev. 55 (2016) 467-481, https://doi.org/10.1016/j.rser.2015.10.122.

[9] C.C. Kung, F. Kong, Y. Choi, Pyrolysis and biochar potential using crop residues and agricultural wastes in China, Ecol. Indicat. 51 (2015) 139-145, https://doi.org/10. 1016/j.ecolind.2014.06.043.

[10] P.R. Oliveira, A.C. Lamy-Mendes, E.I.P. Rezende, A.S. Mangrich, L.H. MarcolinoJunior, M.F. Bergamini, Electrochemical determination of copper ions in spirit drinks using carbon paste electrode modified with biochar, Food Chem. 171 (2015)
426-431, https://doi.org/10.1016/j.foodchem.2014.09.023.

[11] P.R. Oliveira, C. Kalinke, J.L. Gogola, A.S. Mangrich, L.H. Marcolino-Junior, M.F. Bergamini, The use of activated biochar for development of a sensitive electrochemical sensor for determination of methyl parathion, J. Electroanal. Chem. 799 (2017) 602-608, https://doi.org/10.1016/j.jelechem.2017.06.020.

[12] D. Agustini, A.S. Mangrich, M.F. Bergamini, L.H. Marcolino-Junior, Sensitive voltammetric determination of lead released from ceramic dishes by using of bismuth nanostructures anchored on biochar, Talanta 142 (2015) 221-227, https://doi.org/ 10.1016/j.talanta.2015.04.052.

[13] P.R. Oliveira, C. Kalinke, A.S. Mangrich, L.H. Marcolino-Junior, M.F. Bergamini, Copper hexacyanoferrate nanoparticles supported on biochar for amperometric determination of isoniazid, Electrochim. Acta 285 (2018) 373-380, https://doi.org/ 10.1016/j.electacta.2018.08.004.

[14] H. Sun, W.C. Hockaday, C.A. Masiello, K. Zygourakis, Multiple controls on the chemical and physical structure of biochars, Ind. Eng. Chem. Res. 51 (2012) 3587-3597, https://doi.org/10.1021/ie201309r.

[15] J. Kim, S.J. Park, D.H. Min, Emerging approaches for graphene oxide biosensor, Anal. Chem. 89 (2017) 232-248, https://doi.org/10.1021/acs.analchem.6b04248.

[16] C.-M. Tîlmaciu, M.C. Morris, Carbon nanotube biosensors, Front. Chem. 3 (2015) 1-21, https://doi.org/10.3389/fchem.2015.00059.

[17] Sandeep Vashist, John Luong, Handbook of Immunoassay Technologies: Approaches, Performances, and Applications, first ed., Academic Press, Cambridge, 2018.

[18] W. Guo, X. Lin, W. Wang, J. Tian, M. Cong, H. Zhang, Phylogeny and origins of hantaviruses harbored by bats, Insectivores Rodents 9 (2013), https://doi.org/10. 1371/journal.ppat.1003159.

[19] G.G. de Figueiredo, A.A. Borges, G.M. Campos, et al., Diagnosis of hantavirus in fection in humans and rodents in ribeirão preto, state of são paulo, Brazil, Rev. Soc. Bras. Med. Trop. 43 (2010) 348-354 https://doi.org/10.1590/S003786822010000400002

[20] P. Maes, J. Clement, I. Gavrilovskaya, M. Van Ranst, Hantaviruses: immunology, treatment and prevention, Viral Immunol. 17 (2004) 481-497, https://doi.org/10 1089/vim.2004.17.481.

[21] J. Clement, P. McKenna, J. Groen, A. Osterhaus, P. Colson, T. Vervoort, G. van der Groen, H.W. Lee, Epidemiology and laboratory diagnosis of hantavirus (HTV) infections, Acta Clin. Belg. 50 (1995) 9-19, https://doi.org/10.1080/17843286. 1995.11718414.

[22] J. Groen, M. Gerding, J.G.M. Jordans, J.P. Clement, A.D.M.E. Osterhaus, Class and subclass distribution of hantavirus-specific serum antibodies at different times after the onset of nephropathia epidemica, J. Med. Virol. 43 (1994) 39-43, https://doi org/10.1002/jmv.1890430108.

[23] I. Roitt, J. Brostoff, D. Male, Immunology, second ed., Gower Med. Publ. London, 1989.

[24] D. David, Chaplin, Overview of the immune response, J. Allergy Clin. Immunol. 125 (2010), https://doi.org/10.1016/j.jaci.2009.12.980. Overview.

[25] A. Guterres, E.R.S. de Lemos, Hantaviruses and a neglected environmental determinant, One Heal 5 (2018) 27-33, https://doi.org/10.1016/j.onehlt.2017.12. 002.

[26] A.C. Koishi, M.N. Aoki, T.R. Jorge, A.A. Suzukawa, C. Zanluca, S. Levis, C.N. Duarte dos Santos, Development and validation of a point-of-care test for detecting hantavirus antibodies in human and rodent samples, Diagn. Microbiol. Infect. Dis. 85 (2016) 323-327, https://doi.org/10.1016/j.diagmicrobio.2016.04.010.

[27] E.I.P. Rezende, L.C. Angelo, S.S. Dos Santos, A.S. Mangrich, Biocarvão (Biochar) e sequestro de carbono, Rev. Virtual Quim. 3 (2011) 426-433, https://doi.org/10. 5935/1984-6835.20110046.

[28] C. Kalinke, A.S. Mangrich, L.H. Marcolino-Junior, M.F. Bergamini, Biochar prepared from castor oil cake at different temperatures: a voltammetric study applied for $\mathrm{Pb} 2+, \mathrm{Cd} 2+$ and $\mathrm{Cu} 2+$ ions preconcentration, J. Hazard Mater. 318 (2016) 526-532, https://doi.org/10.1016/j.jhazmat.2016.07.041.

[29] H.P. Boehm, Some aspects of the surface chemistry of carbon blacks and other carbons, Carbon N. Y. 32 (1994) 759-769, https://doi.org/10.1016/0008-6223(94) 90031-0.

[30] Y. Li, J. Shao, X. Wang, Y. Deng, H. Yang, H. Chen, Characterization of modified biochars derived from bamboo pyrolysis and their utilization for target component (furfural) adsorption, Energy Fuels 28 (2014) 5119-5127, https://doi.org/10. 1021/ef500725c.

[31] P. Oleszczuk, I. Jośko, B. Futa, S. Pasieczna-Patkowska, E. Pałys, P. Kraska, Effect of pesticides on microorganisms, enzymatic activity and plant in biochar-amended soil, Geoderma 214-215 (2014) 10-18, https://doi.org/10.1016/j.geoderma.2013. 10.010 .

[32] C. Wang, Q. Yan, H.B. Liu, X.H. Zhou, S.J. Xiao, Different EDC/NHS activation mechanisms between PAA and PMAA brushes and the following amidation reactions, Langmuir 27 (2011) 12058-12068, https://doi.org/10.1021/la202267p.

[33] G. Settanni, J. Zhou, T. Suo, S. Schöttler, K. Landfester, F. Schmid, V. Mailänder, Protein corona composition of poly(ethylene glycol)-and poly (phosphoester)coated nanoparticles correlates strongly with the amino acid composition of the protein surface, Nanoscale 9 (2017) 2138-2144, https://doi.org/10.1039/ c6nr07022a.

[34] R. Pauliukaite, M. Ghica, Comparative study of different cross-linking agents for the immobilization of functionalized carbon nanotubes within a chitosan film supported on a graphite-epoxy composite electrode, Anal. Chem. 81 (2009) 5364-5372, https://doi.org/10.1021/ac900464z.

[35] R. Reverberi, L. Reverberi, Factors affecting the antigen-antibody reaction, Blood Transfus. 5 (2007) 227-240, https://doi.org/10.2450/2007.0047-07.

[36] A. Alminaite, V. Backström, A. Vaheri, A. Plyusnin, Oligomerization of hantaviral nucleocapsid protein: charged residues in the $\mathrm{N}$-terminal coiled-coil domain 
contribute to intermolecular interactions, J. Gen. Virol. 89 (2008) 2167-2174, https://doi.org/10.1099/vir.0.2008/004044-0.

[37] P. He, Z. Wang, L. Zhang, W. Yang, Development of a label-free electrochemical immunosensor based on carbon nanotube for rapid determination of clenbuterol, Food Chem. 112 (2009) 707-714, https://doi.org/10.1016/j.foodchem.2008.05. 116.

[38] R.M. Wazen, S. Kuroda, C. Nishio, K. Sellin, J.B. Brunski, A. Nanci, Gene expression profiling and histomorphometric analyses of the early bone healing response around nanotextured implants, Nanomedicine 8 (2014) 1385-1395, https://doi. org/10.2217/nnm.12.167.Gene.

[39] T. Thomas, R.J. Mascarenhas, C. Nethravathi, M. Rajamathi, B.E. Kumara Swamy, Graphite oxide bulk modified carbon paste electrode for the selective detection of dopamine: a voltammetric study, J. Electroanal. Chem. 659 (2011) 113-119, https://doi.org/10.1016/j.jelechem.2011.05.011.
[40] Z. Chen, X. Xiao, B. Chen, L. Zhu, Quantification of chemical states, dissociation constants and contents of oxygen-containing groups on the surface of biochars produced at different temperatures, Environ. Sci. Technol. 49 (2015) 309-317, https://doi.org/10.1021/es5043468.

[41] Z. Grabarek, J. Gergely, Zero-length crosslinking procedure with the use of active esters, Anal. Biochem. 185 (1990) 131-135, https://doi.org/10.1016/00032697(90)90267-D.

[42] S.K. Vashist, Comparison of 1-Ethyl-3-(3-Dimethylaminopropyl) Carbodiimide based strategies to crosslink antibodies on amine-functionalized platforms for immunodiagnostic applications, Diagnostics 2 (2012) 23-33, https://doi.org/10. 3390/diagnostics2030023.

[43] S.K. Vashist, P.B. Luppa, L.Y. Yeo, A. Ozcan, J.H.T. Luong, Emerging technologies for next-generation point-of-care testing, Trends Biotechnol. 33 (2015) 692-705, https://doi.org/10.1016/j.tibtech.2015.09.001. 